\title{
Comparison and analysis of calculation of Bridge backwater based on Mike21 hydrodynamic model
}

\author{
Jiang Chuan $\mathrm{Liu}^{1,2, \mathrm{a}}$, Zhu Qiu $\mathrm{Hu}^{1, \mathrm{~b}}$,Mao Yuan $\mathrm{Zhu}^{1, \mathrm{c}}$ \\ ${ }^{1}$ Dept.of Hydraulic \& environmental engineering, Changchun Institute of Technology, Changchun, Jilin, China. \\ ${ }^{2}$ Jilin Province Science and Technology Innovation Center for Physical Simulation and Security of Water Resources and \\ Electric Power Engineering, Changchun, Jilin, China.
}

\begin{abstract}
The construction of bridges and other structures across the river will affect the flood discharge capacity and local water potential of the river.Based on navier-Stokes equation of MIKE21FM hydrodynamic module, this paper carries out two-dimensional numerical simulation of part of Shixi River. By optimizing the grid near the piers to reduce the difference brought by the terrain generalized grid of the real river, it simulates and analyzes the length of the curve of yong-high and Yong-water under different flood frequencies, the Nash-Sutcliffe efficiency coefficient and relative error analysis are used to verify the rationality of the results. The simulation results can accurately reflect the real changes of river water level, It provides a theoretical basis for flood impact analysis.
\end{abstract}

\section{Introduction}

At present, scholars at home and abroad have made fruitful research achievements on the impact of Bridges across rivers on river regime and accumulated a lot of engineering experience. They proposed the empirical formula of bridge yong Shui under different working conditions $^{[1]}$, which has been widely applied in engineering due to its simple form and easy application. With the development of computer technology, the limitations of traditional empirical formulas are gradually revealed, and numerical simulation is developing towards precision and visualization. Mike21, as a bidimensional simulation tool for rivers and lakes, has been widely used and studied in China $^{[2-5]}$.

Pingshan River is a first-grade tributary of Danshui River, one of the five rivers in Shenzhen. Shixi River is a first-grade tributary of Pingshan River, located in the northeast of Pingshan River basin, originating from Bijia Mountain in Huizhou (elevation $717.5 \mathrm{~m}$ ), and flowing into the main stream of Pingshan River from Tugang Ling downstream. The river length is $12.328 \mathrm{~km}$, with an average specific drop of $11.7 \%$, and the basin area is $23.33 \mathrm{~km}^{2}$, among which the basin area in Shenzhen is $5.83 \mathrm{~km}^{2}$. The upper part of Shixi River is located in Daya Bay District, Huizhou, which is known as Shitou River locally. It originates from The Bijia Mountain (elevation $717.5 \mathrm{~m}$ ) bordering Shenhui. From east to west, it flows through Tangheng and Tangbu before entering The territory of Shenzhen. Shitou River is located in Huizhou and has a tributary, about $3.0 \mathrm{~km}$ in length, with a rainwater harvesting area of about $3.5 \mathrm{~km}^{2}$.

\section{Model selection and model construc tion}

\subsection{Model Selection}

The commonly used mathematical simulation software for the simulation and analysis of rivers and lakes include MIKE $^{[6]}$, FLUENT, Hec-RAS ${ }^{[7]}$, etc., among which MIKE software has been widely applied in flood submergence, water quality analysis of water sources, and flood discharge capacity of river channels, and has accumulated a lot of engineering experience ${ }^{[8-10]}$.

MIKE21FM model developed by the Danish institute of hydraulic to saint venant equations as the basic control equation of the hydrodynamic module is based on the numerical solution of two-dimensional shallow water equation, the integral along the depth of incompressible Reynolds averaged Navier - Stokes equations, can be used to simulate the water level and flow of all kinds of force to produce change, space discrete finite volume method is used to calculate area, has the very good conservation of nature, can accurate processing rapids, discontinuous solution.

\subsection{Model building}

\subsubsection{Model calculation range}

In order to better study the terrain conditions of the reach, this paper derived the data based on the measured terrain data and combined with Arcgis software elements turning




points, applied the unstructured grid to process the channel, and interpolated the nearby scattered points through the interpolation method of adjacent points.

\subsubsection{Generalizations of main river structures}

This simulation area involved a total of the Shixi River Bridge at stake $0+235$ and the Shixi River Bridge at stake
0+936.29. Considering that the two bridges are not under water, the generalization of the bridge is changed to the generalization of the bridge piers. The road bridge has a width of $9 \mathrm{~m}$ and a total of 4 piers. The Shixi River Bridge has a width of $18 \mathrm{~m}$ and a total of 8 piers, each of which has 4 piers. The distance between single-row piers is $20 \mathrm{~m}$.

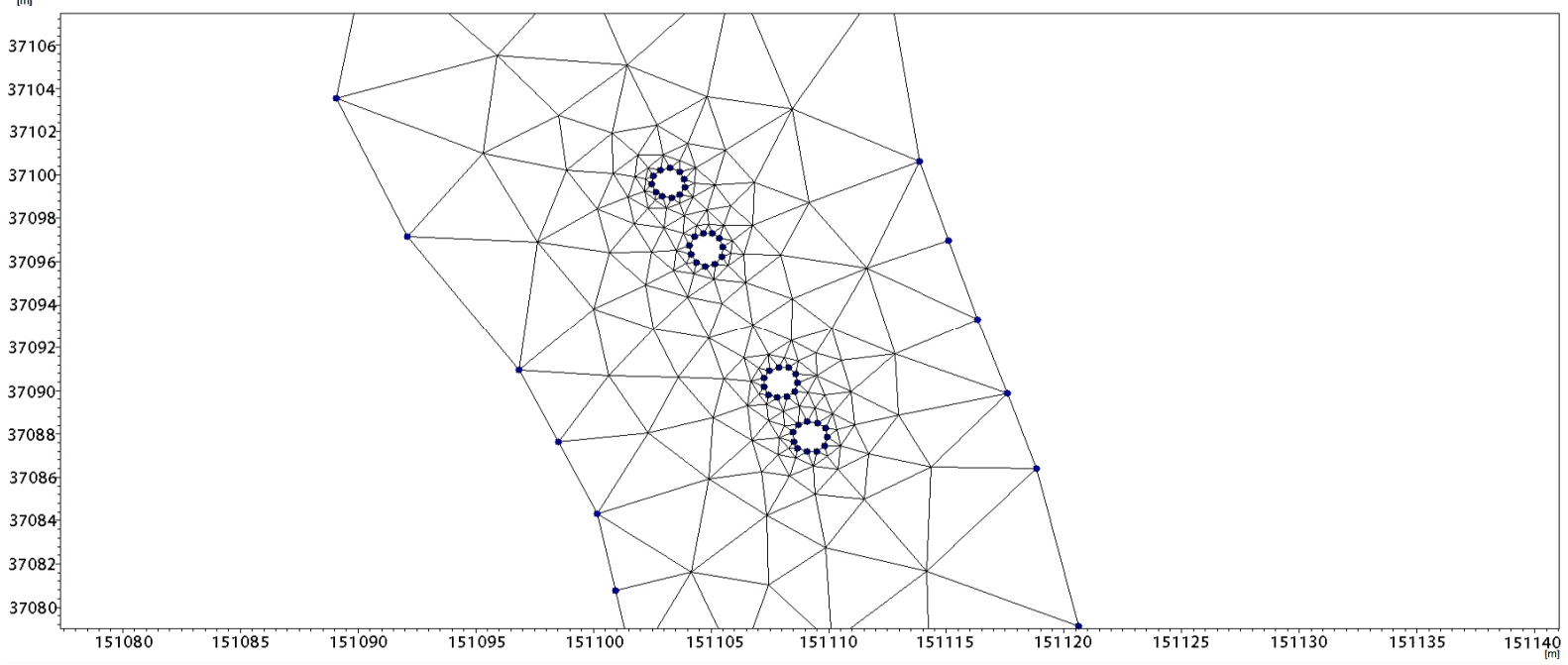

Fig.1 sketch map of Environment bridge

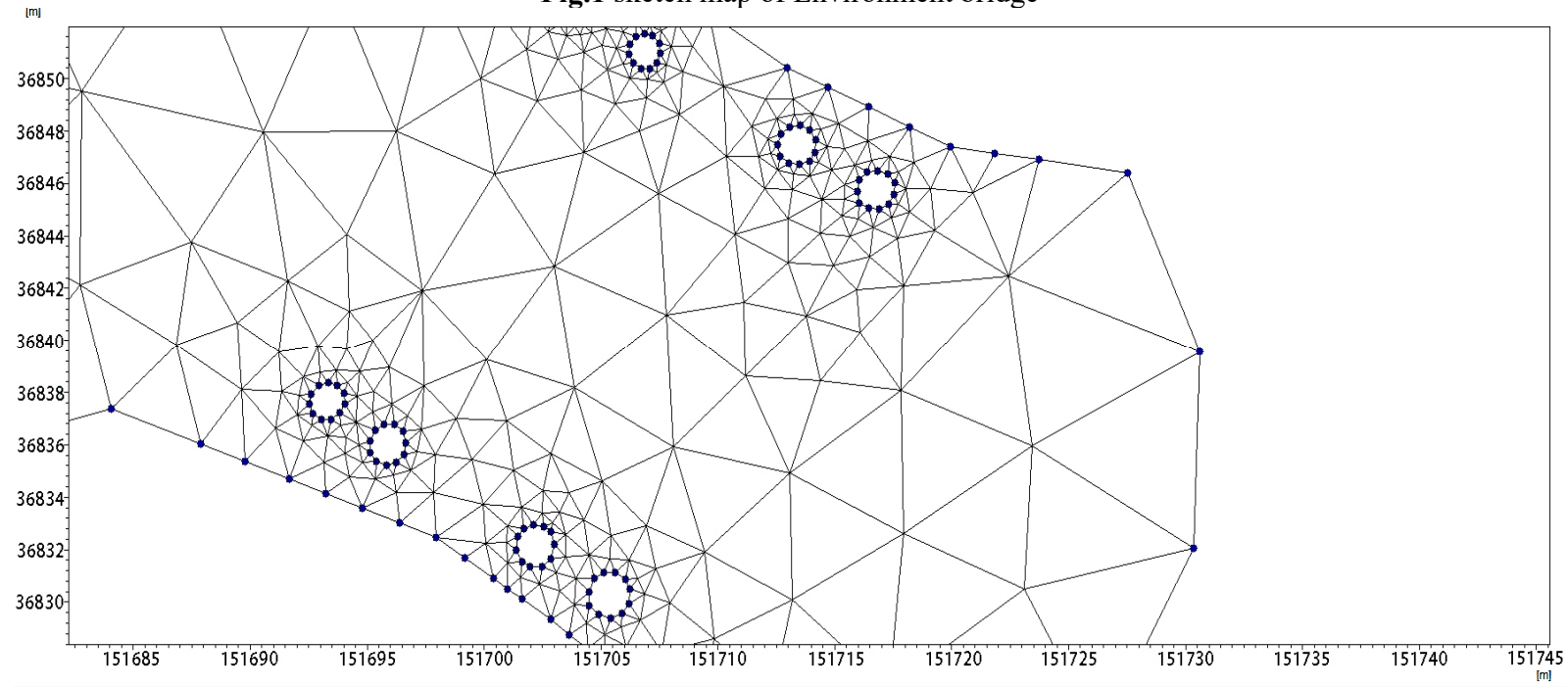

Fig.2 sketch map of Shixi River bridge

\subsubsection{Boundary Condition Setting}

The boundary condition of the model is the discharge-water level boundary condition. Taking the designed peak discharge of $\mathrm{K} 2+144$ section as the upper boundary of constant discharge, the once-in-20-year peak discharge of $\mathrm{K} 2+144$ section is $263.84 \mathrm{~m}^{3} / \mathrm{s}$, and the once-in-50-year peak discharge of $318.93 \mathrm{~m}^{3} / \mathrm{s}$, respectively, the lower boundary is the water level of $\mathrm{K} 0$ +000 section corresponding to the flood peak discharge.

\section{Model simulation validation}

The Shixi River has no measured runoff and flood data, so the design flood of every section in the basin is calculated by using the method of indirect derivation of design flood from design rainstorm, methods Flood Analysis and calculation were carried out by using the method of comprehensive unit hydrograph and the method of inference formula in \&quot; the chart of rainstorm runoff check and calculation in Guangdong Province\&quot; The difference between the two methods is less than $20 \%$, so the synthetic unit hydrograph is used. Two methods are proposed for model validation, namely, the relative error value and Nash-Sutcliffe efficiency coefficient.

The relative error calculation formula:

$$
R E_{P}=\frac{\left|\mathrm{q}_{\mathrm{t}}^{\mathrm{obs}}-\mathrm{q}_{\mathrm{t}}^{\mathrm{sim}}\right|}{\mathrm{H}} \times 100 \%
$$

In the formula, $\mathrm{q}_{\mathrm{t}}{ }^{\text {obs }}$ is the measured value, $\mathrm{m}^{3} / \mathrm{s}$ and $\mathrm{q}_{\mathrm{t}}^{\text {sim }}$ is the simulated value, $\mathrm{m}^{3} / \mathrm{s}$. $\mathrm{H}$ is average water depth of section. 
Nash-Sutcliffe efficiency coefficient formula:

$$
R_{N S}=1-\frac{\sum_{t=1}^{N}\left(\mathrm{q}_{\mathrm{t}}^{\mathrm{obs}}-\mathrm{q}_{\mathrm{t}}^{\text {sim }}\right)^{2}}{\sum_{t=1}^{N}\left(\mathrm{q}_{\mathrm{t}}^{\mathrm{obs}}-\mathrm{q}_{\mathrm{t}}^{-\mathrm{obs}}\right)^{2}}
$$

In the formula, $\mathrm{N}$ is the number of data; $\mathrm{q}_{\mathrm{t}}{ }^{-\mathrm{obs}}$ is the data mean; the rest of the symbols have the same meaning as before.

In order to test the rationality of the simulation results of this model, the design water level $\mathrm{P}=5 \%$ flood peak discharge is taken as an example,taking the design flood peak discharge of $\mathrm{K} 2+144$ section as the upper boundary of constant flow and the water level of $\mathrm{K} 0+$ 000 section corresponding to the flood peak discharge as the lower boundary, the results of water surface profile calculation are compared and analyzed to verify the rationality of the model. The results are shown in Table 1 .

Table 1.Comparison of model simulation results and calculation results

\begin{tabular}{|c|c|c|c|c|c|c|}
\hline Pile number & Location name & Design $\operatorname{result} / \mathrm{m}$ & Simulation results $/ \mathrm{m}$ & Error/m & Relative error/\% & $\mathrm{N}$-sCoefficient $/ \mathrm{R}_{\mathrm{NS}}$ \\
\hline $0+235.00$ & Environment & 29.630 & 29.458 & 0.172 & $3.59 \%$ & \multirow{24}{*}{0.99} \\
\hline $0+300.00$ & bridge & 29.720 & 29.554 & 0.166 & $3.52 \%$ & \\
\hline $0+400.00$ & & 29.750 & 29.705 & 0.045 & $1.02 \%$ & \\
\hline $0+500.00$ & & 29.750 & 29.566 & 0.184 & $4.28 \%$ & \\
\hline $0+600.00$ & & 29.770 & 29.614 & 0.156 & $4.04 \%$ & \\
\hline $0+700.00$ & & 29.820 & 29.727 & 0.093 & $2.47 \%$ & \\
\hline $0+799.99$ & & 30.070 & 30.195 & -0.125 & $3.21 \%$ & \\
\hline $0+899.99$ & & 29.920 & 29.861 & 0.059 & $1.75 \%$ & \\
\hline $0+936.29$ & \multirow{16}{*}{$\begin{array}{l}\text { Shixi River } \\
\text { bridge }\end{array}$} & 30.540 & 30.647 & -0.107 & $2.56 \%$ & \\
\hline $0+999.99$ & & 30.700 & 30.599 & 0.101 & $2.36 \%$ & \\
\hline $1+038.18$ & & 31.050 & 30.904 & 0.146 & $3.60 \%$ & \\
\hline $1+099.98$ & & 31.030 & 31.013 & 0.017 & $0.44 \%$ & \\
\hline $1+199.99$ & & 31.010 & 31.127 & -0.117 & $3.31 \%$ & \\
\hline $1+299.97$ & & 31.030 & 31.152 & -0.122 & $3.72 \%$ & \\
\hline $1+399.97$ & & 31.150 & 31.17 & -0.02 & $0.67 \%$ & \\
\hline $1+499.97$ & & 31.280 & 31.376 & -0.096 & $3.36 \%$ & \\
\hline $1+599.97$ & & 31.790 & 31.875 & -0.085 & $2.79 \%$ & \\
\hline $1+699.95$ & & 31.860 & 31.952 & -0.092 & $3.27 \%$ & \\
\hline $1+799.95$ & & 32.060 & 32.118 & -0.058 & $2.16 \%$ & \\
\hline $1+823.50$ & & 32.080 & 32.139 & -0.059 & $2.23 \%$ & \\
\hline $1+899.94$ & & 32.570 & 32.593 & -0.023 & $0.80 \%$ & \\
\hline $1+999.94$ & & 33.710 & 33.601 & 0.109 & $2.94 \%$ & \\
\hline $2+099.94$ & & 33.770 & 33.633 & 0.137 & $3.96 \%$ & \\
\hline $2+144.59$ & & 33.910 & 33.875 & 0.035 & $1.01 \%$ & \\
\hline
\end{tabular}

From the table, it can be seen that the result of the model is basically consistent with the river topography. The error between the result of the design water surface profile and the result of the simulation water surface profile is- $0.125 \sim 0.184$, and the Nakhi people efficiency coefficient is more than 0.8 in the verification process, the relative error is between $0.44 \%$ and $4.28 \%$, which is less than $5 \%$. The simulation error is small, and the model meets the verification precision. However, due to the lack of data in the river channel, it is inevitable that there will be some errors in the modeling process, resulting in the water surface line and design data can not fully coincide.

\section{Calculation result of backwater}

\subsection{Empirical formula calculation result}

Henderson's formula:

$$
\Delta Z_{M}=(1+\eta)\left(\frac{{\overline{V_{M}}}^{2}}{2 \mathrm{~g}}-\frac{\bar{V}^{2}}{2 \mathrm{~g}}\right)
$$

In the formula, $\triangle Z_{M}$ denotes the maximum backwater height before the bridge, $\mathrm{m} ; \eta$ is the coefficient related to the shape of the pier, the rectangle pier is 0.35 , the circle pier is 0.18 . $\mathrm{V}_{\mathrm{M}}$ is the average velocity under the bridge, $\mathrm{m} / \mathrm{s} ; \mathrm{V}$ is the average velocity of section, $\mathrm{m} / \mathrm{s}$. The formula is proposed by Henderson by analyzing the local energy loss caused by the pier resistance. The research Institute of Railway Bridge in China has verified the rationality of the parameter value of the formula based on a large number of field investigation data ${ }^{[11]}$.

The backwater curve length is calculated as follows:

Backwater curve length:

$$
L=\frac{2 \Delta Z_{M}}{I}
$$

In the formula, $\mathrm{I}$ is the natural water surface ratio of the bridge section, and The shixi River Bridge is 1.3\%; Environmental Park Road bridge take $0.55 \%$.

Table 2.calculation value of backwater experience formula in front of bridge with different frequency

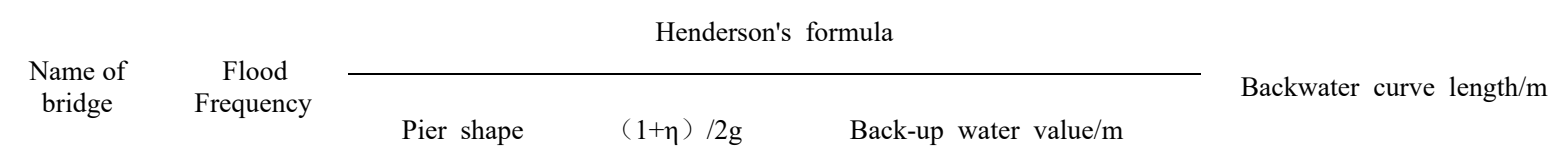




\begin{tabular}{lccccc}
\hline & $5 \%$ & Circular shape & 0.06 & 0.15 & 545 \\
$\begin{array}{c}\text { Environment } \\
\text { bridge }\end{array}$ & $2 \%$ & Circular shape & 0.06 & 0.22 & 800 \\
\cline { 2 - 5 } & $5 \%$ & Circular shape & 0.06 & 0.33 & 508 \\
\hline $\begin{array}{c}\text { Shixi River } \\
\text { bridge }\end{array}$ & $2 \%$ & Circular shape & 0.06 & 0.41 & 631 \\
\hline
\end{tabular}

\subsection{Model calculation results}

Table 3. calculation values of backwater model in front of bridge with different frequencies

\begin{tabular}{|c|c|c|c|c|c|c|c|}
\hline \multirow{3}{*}{ Pile number } & \multirow{3}{*}{ Location name } & \multicolumn{6}{|c|}{ Flood level/m } \\
\hline & & \multicolumn{2}{|c|}{ River channel (No Bridge) $/ \mathrm{m}$} & \multicolumn{2}{|c|}{ River channel (Bridge) $/ \mathrm{m}$} & \multicolumn{2}{|c|}{ Back-up water value $/ \mathrm{m}$} \\
\hline & & $\mathrm{P}=2 \%$ & $\mathrm{P}=5 \%$ & $\mathrm{P}=2 \%$ & $\mathrm{P}=5 \%$ & $\mathrm{P}=2 \%$ & $\mathrm{P}=5 \%$ \\
\hline $0+235.00$ & Environment & 29.93 & 29.36 & 30.07 & 29.46 & & \\
\hline $0+300.00$ & bridge & 29.97 & 29.40 & 30.22 & 29.55 & & \\
\hline $0+400.00$ & & 30.09 & 29.59 & 30.24 & 29.71 & 0.14 & 0.10 \\
\hline $0+500.00$ & & 30.11 & 29.47 & 30.24 & 29.57 & 0.25 & 0.15 \\
\hline $0+600.00$ & & 30.17 & 29.56 & 30.13 & 29.61 & 0.15 & 0.12 \\
\hline $0+700.00$ & & 30.25 & 29.71 & 30.25 & 29.73 & 0.13 & 0.10 \\
\hline $0+799.99$ & & 30.44 & 30.19 & 30.47 & 30.20 & 0.08 & 0.05 \\
\hline $0+899.99$ & & 30.27 & 29.86 & 30.28 & 29.86 & 0.06 & 0.02 \\
\hline $0+936.29$ & Shixi River & 30.87 & 30.45 & 31.00 & 30.65 & 0.03 & 0.01 \\
\hline $0+999.99$ & bridge & 30.97 & 30.35 & 31.19 & 30.60 & 0.01 & \\
\hline $1+038.18$ & & 30.98 & 30.56 & 31.40 & 30.90 & 0.13 & 0.20 \\
\hline $1+099.98$ & & 31.01 & 30.73 & 31.37 & 31.01 & 0.22 & 0.25 \\
\hline $1+199.99$ & & 31.10 & 30.91 & 31.35 & 31.13 & 0.42 & 0.34 \\
\hline $1+299.97$ & & 31.07 & 30.89 & 31.37 & 31.15 & 0.36 & 0.28 \\
\hline $1+399.97$ & & 31.18 & 31.07 & 31.28 & 31.17 & 0.25 & 0.22 \\
\hline $1+499.97$ & & 31.69 & 31.38 & 31.74 & 31.38 & 0.30 & 0.26 \\
\hline $1+599.97$ & & 32.07 & 31.88 & 32.10 & 31.88 & 0.10 & 0.10 \\
\hline $1+699.95$ & & 32.09 & 31.95 & 32.11 & 31.95 & 0.05 & \\
\hline $1+799.95$ & & 32.27 & 32.12 & 32.29 & 32.12 & 0.03 & \\
\hline $1+823.50$ & & 32.33 & 32.14 & 32.33 & 32.14 & 0.02 & \\
\hline $1+899.94$ & & 32.90 & 32.59 & 32.90 & 32.59 & 0.02 & \\
\hline $1+999.94$ & & 34.15 & 33.60 & 34.15 & 33.60 & & \\
\hline $2+099.94$ & & 34.21 & 33.63 & 34.21 & 33.63 & & \\
\hline $2+144.59$ & & 34.37 & 33.88 & 34.37 & 33.88 & & \\
\hline
\end{tabular}

From the above data, it can be seen that the bridge pier reduces the flow area under the bridge and causes the upper reaches of the bridge to Produce backwater. From Table 2 and Table 3, it can be seen that the back-up water value of the Environment Garden Road Bridge is $0.15 \mathrm{~m}$ once flood in 20 years through the empirical formula, the results are consistent with the model simulation. The back-up water value of the 50-year flood is $0.22 \mathrm{~m}$, the model simulation result is $0.25 \mathrm{~m}$, the back-up water value of the 20 -year flood is $0.33 \mathrm{~m}$, the model simulation result is $0.34 \mathrm{~m}$, the 50 -year back-up water value of the 50 -year flood is $0.41 \mathrm{~m}$, the result of the model is $0.42 \mathrm{~m}$, and the result of the empirical formula is consistent with that of the model. According to the above data, the result of the model is slightly higher than that of the empirical formula, its error may be due to the lack of complex river terrain information, but its error is within the controllable range, the specific data as shown in the table above.

\section{Conclusion}

Taking some sections of the Shixi River as an example, the MIKE21 hydrodynamic model is established to simulate the flood-carrying capacity of the river under the flood frequency of $\mathrm{P}=2 \%$ and $\mathrm{P}=5 \%$, and the situation of the backwater of the two bridges in the river channel, compared with the calculated results of the empirical formula, the error of the model is reasonable, and its yong-gao value is within a reasonable range, which shows that the model is reliable and can reflect the influence of different frequency floods on the river course, at the same time, the model can clearly reflect the changes of water level, flow velocity and flow field near the bridge, and can provide technical support for engineering decision.

\section{Acknowledgments}

This paper is one of the stage achievements of the 
Science and technology research project of Jilin Prov incial Department of Education(Grant[2015] No .30 $1)$.

\section{References}

1. Yuan Xiongyan and $\mathrm{Xu}$ Delong, application of Danish MIKE21 model in calculation of backwater of bridge crossing. People's Yangtze River, 2006(04): 31-32 52.

2. Cong Xiaohong, Wang Junying and Tang Weiming, analysis of influence factors on river flood control hydraulic calculation across administrative regions. People's Yellow River, 2020: Pages 1-5.

3. Su Chang, application and applicability analysis of several bridge pier generalization methods in Mike 21 FM model. People's Pearl River, 2019. 40(08) : Pages 123-126.

4. Liu Xiaoqin, Liu Guolong, Wang Zhen, and MIKE series models in flood simulation of flood storage and Detention Area. China Rural Water Conservancy and Hydropower, 2020(06): 10-15, 20.

5. Wang Xiaomin and Chen Xue, based on Mike 212-d numerical simulation of backwater rule in front of the bridge. Water Science and technology and economics, 2016. 22(11) : pages 73-75.

6. Li Hang, Dinman and Xu Guixin, numerical simulation of flood routing in Yinma River, Jilin Province. Water Science and technology and economics, 2020. 26(06) : pages 42-46

7. Yu Zicheng, Mike 21 and HEC-RAS in pushing ball on water line. Journal of Hebei Institute of Water Conservancy and hydropower, 2019. (04)

8. Liu Weilin, if Fan, Liu Lina, etc. . Impact analysis of flood carrying capacity of Nanfeng County Landscape Dam based on Mike Model [J] . Water and hydropower technology, 2020,51(4) : 57-66.

9. He wanlin and Liu Wei, based on the Mike Model, the simulation study of the Cuijiaqiao flood storage and detention area in Henan Province and the publication of the results. China Flood Control and Drought Relief, 2019. 29(11) : pages 54-57.

10. Zhou Ying et AL, Mike21-based water quality prediction and impact analysis. Hydroelectric Energy Science, 2020. 38(04) : Pages 43-46.

11. Lu Hao (born 1947). Summary of Bridge Backwater Research[J] . Railway Construction, 1980(3) : 9-13. 